\title{
The Diagnostic Yield and Safety of Ultrasound-Assisted Transthoracic Biopsy of Mediastinal Masses
}

\author{
Coenraad F.N. Koegelenberg ${ }^{a} \quad$ Andreas H. Diacon $^{a}{ }^{a b}$ Elvis M. Irusen ${ }^{a}$ \\ Florian von Groote-Bidlingmaier ${ }^{\mathrm{a}}$ Abdurasiet Mowlana ${ }^{\mathrm{a}}$ Colleen A. Wright ${ }^{\mathrm{c}}$ \\ Mercia Louw ${ }^{c}$ Pawel T. Schubert ${ }^{c}$ Chris T. Bolliger ${ }^{a}$ \\ ${ }^{a}$ Division of Pulmonology, Department of Medicine, University of Stellenbosch and Tygerberg Academic Hospital, \\ ${ }^{b}$ Division of Medical Physiology, Department of Biomedical Sciences, University of Stellenbosch and Tygerberg \\ Academic Hospital, and ${ }^{\mathrm{C}}$ Division of Anatomical Pathology, Department of Pathology, University of Stellenbosch \\ and National Health Laboratory Service, Cape Town, South Africa
}

\section{Key Words}

Biopsy $\cdot$ Mediastinal mass $\cdot$ Ultrasound

\section{Abstract}

Background: Ultrasound (US)-assisted transthoracic biopsy offers a less invasive alternative to surgical biopsy in the setting of mediastinal masses. Objectives: The aim of this 1-year prospective study was to assess the diagnostic yield and safety of a novel single-session sequential approach of USassisted transthoracic fine-needle aspirations (TTFNA) with rapid on-site evaluation (ROSE) followed by cutting needle biopsies (CNB) performed by physicians on patients with anterosuperior mediastinal masses. Methods: US-assisted TTFNA with ROSE was performed on 45 consecutive patients (49.5 \pm 27.7 years, 24 males), immediately followed by CNB where a provisional diagnosis of epithelial carcinoma or tuberculosis could not be established, provided a safety range could be assured. Results: TTFNA alone was deemed adequate by means of ROSE in $27(60 \%)$ patients. CNB could be performed in 17 of the remaining 18 . The on-site diagnosis corresponded to the final diagnosis in 26/45 (57.8\%). An accurate cytological diagnosis was made in 33 (73.3\%), and was more likely to be diagnostic in epithelial carcinoma and tuberculosis (28/30) than all other pathologies $(5 / 15, p<$ 0.001 ). CNB yielded a diagnosis in $15 / 17$ (88.2\%). Overall, $42 / 45$ patients were diagnosed by the single-session approach (93.3\%). The final diagnoses included 41 neoplasms, with small cell lung cancer $(n=13)$ the commonest diagnosis. We observed no pneumothorax or major haemorrhage. Conclusions: A single-session sequential approach of USassisted TTFNA with ROSE followed by CNB, where indicated, has a high diagnostic yield for anterosuperior mediastinal masses, is safe and offers an alternative to surgical biopsy.

Copyright $\odot 2010$ S. Karger AG, Basel

\section{Introduction}

The differential diagnosis of mediastinal masses is broad and computed tomography (CT) scanning followed by biopsy is indicated in practically all cases [1-5]. Tissue is most often harvested by means of mediastinoscopy, mediastinotomy or related surgical procedures [2-6]. Although the diagnostic yield of such an approach exceeds $90 \%$, surgical biopsies carry a complication rate

\section{KARGER}

Fax +4161306 1234

E-Mail karger@karger.ch

www.karger.com (c) 2010 S. Karger AG, Basel

$0025-7931 / 11 / 0812-0134 \$ 38.00 / 0$

Accessible online at:

www.karger.com/res
Dr. Coenraad F.N. Koegelenberg

Division of Pulmonology, Department of Medicine, University of Stellenbosch PO Box 19063, Tygerberg, 7505

Cape Town (South Africa)

Tel. +27 21938 9243, Fax +27 21933 3591, E-Mail coeniefn@ @un.ac.za 

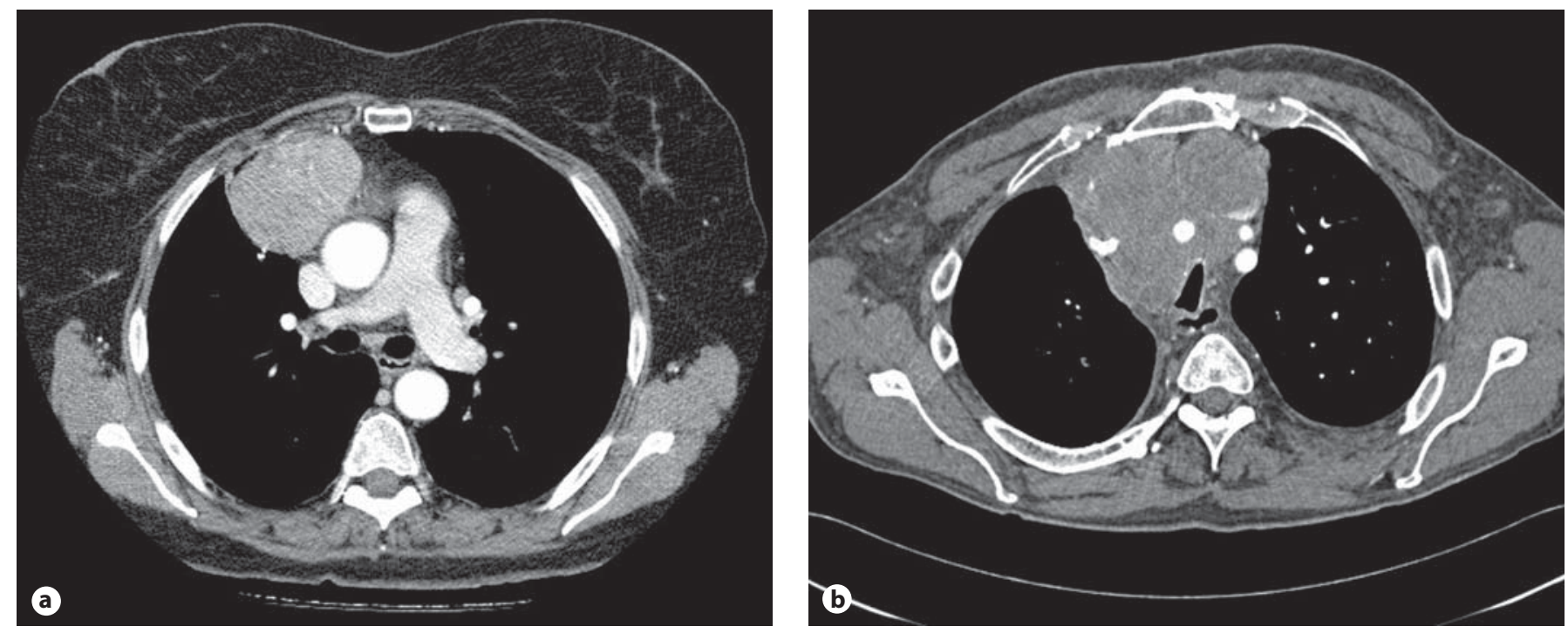

Fig. 1. a CT scan of one of the study subjects shows a distinct anterosuperior mediastinal mass, which was proven to be a thymoma. b An example of an extensive mediastinal mass lesion which in this particular case was found to be due to small cell lung cancer.

of up to $5 \%$ [2-5]. Moreover, these procedures usually need to be performed in theatre under general anaesthesia and require significant expertise and resources [3-5].

Transthoracic ultrasound (US) has become a valuable guide for interventional procedures [7,8], and plays an increasing role in biopsies of the chest wall, pleura and peripheral lung [9-13]. US-assisted biopsies of mediastinal masses were first described by Saito et al. [14] two decades ago, enabling them to diagnose $87 \%$ of all malignant tumours and $67 \%$ of benign masses. Despite these promising findings, US-assisted biopsies have as yet failed to gain popularity amongst clinicians, possibly because subsequent investigators generally utilised only cutting needle biopsies (CNB) $[15,16]$ and were almost exclusively specialist interventional radiologists [17-21].

US-assisted transthoracic fine-needle aspiration (TTFNA) and CNB in the setting of chest wall, pleural and pulmonary malignancies abutting the chest wall have a very high diagnostic yield and are safe, even in the hands of non-radiologists [10-12]. The use of TTFNA with rapid on-site evaluation (ROSE) and CNB has been shown to be complementary $[11,12,22]$. In our previous studies, we found that TTFNA with ROSE of intrathoracic mass lesions has a significantly higher sensitivity than $\mathrm{CNB}$ alone in diagnosing bronchogenic carcinoma, but that CNB remains superior in noncarcinomatous tumours and in benign lesions [10-12, 22]. The addition of ROSE therefore potentially allows for a single-session ap- proach, with US-assisted TTFNA followed by CNB limited to those cases where diagnostically useful material could not be confirmed [11, 12, 22].

The main aim of this prospective study was to assess the diagnostic yield and safety of a novel, single-session sequential approach of US-assisted TTFNA with ROSE followed by CNB performed by physicians in the setting of anterosuperior mediastinal masses.

\section{Materials and Methods}

\section{Study Population}

All adult patients ( $\geq 18$ years) referred to the Division of Pulmonology of Tygerberg Academic Hospital with an anterosuperior mediastinal mass lesion on contrasted CT scan were potential candidates for this 1-year prospective observational study. Our institution is a 1,200-bed academic hospital in Cape Town, South Africa. It is one of two referral centres and renders a tertiary service to a population of approximately 1.5 million people. The Health Research Ethics Committee of Stellenbosch University approved the study (project No. N09/05/136). Written informed consent was obtained from all subjects on enrolment and prior to any invasive procedures.

For the purposes of the study we considered the anterosuperior compartment of the mediastinum as the space posterior to the sternum and anterior to the heart and brachiocephalic vessels, extending from the thoracic inlet to the diaphragm [23]. Patients with a distinct mass lesion that was either confined to the anterosuperior mediastinum (fig. 1a) or where the mediastinum was extensively involved by a mass lesion with the epicentre in the an- 


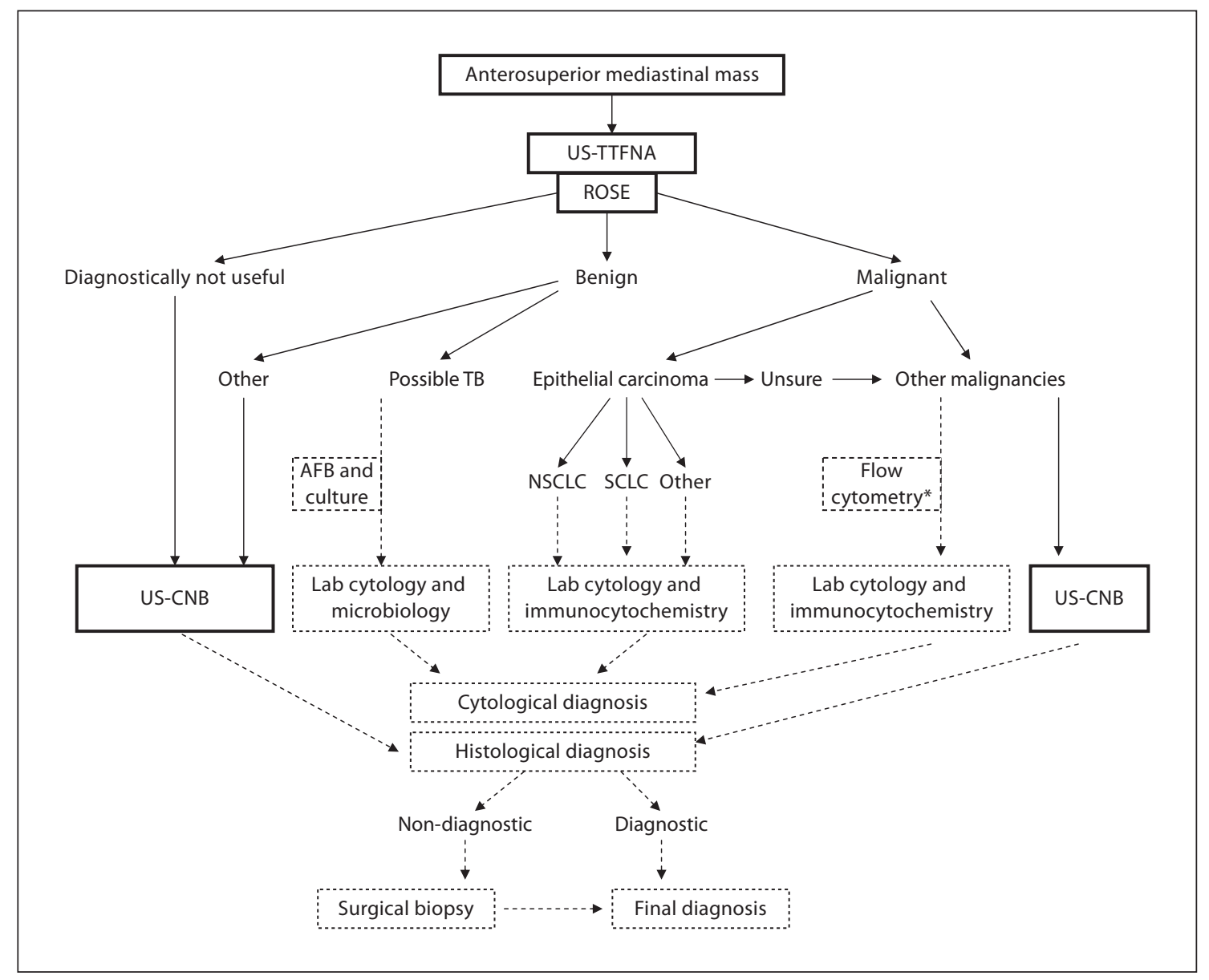

Fig. 2. Scheme of the general diagnostic approach. Solid lines refer to on-site activities, and dotted lines to all laboratory and subsequent procedures. The cytopathologist first commented on the presence or absence of diagnostically useful material obtained during each individual pass. Where diagnostically useful material was present, the cytopathologist was asked to make a provisional diagnosis of malignant or benign pathology. Where malignant cells were present, the pathologist provisionally typed the specimens into one of two main categories: (1) epithelial carcinomas or (2) other malignancies. Epithelial carcinomas were subtyped into either non-small cell lung cancer, small cell lung cancer, other epithelial carcinomas (including thyroid) or epithelial carcinoma of unsure origin. In case of malignancies other than epithelial carcinoma, the cytopathologist was asked to provide

terosuperior mediastinum (fig. 1b) were invited to participate in the study, provided that the mass lesion abutted the anterior chest wall with an interface of at least $1 \mathrm{~cm}$ in two dimensions and no known coagulopathy was present.

\section{Transthoracic US}

A consultant respiratory physician performed the sonography (Toshiba Just Vision 200 SSA-320A; Toshiba Medical Systems Corporation, Tochigi-ken, Japan) in a bronchoscopy suite without provisional diagnosis where possible and to suggest further investigations including flow cytometry. In the case of benign pathology, the specimens were typed into two main categories: (1) suspected tuberculosis and (2) other pathology. Further aspirates for cultures for mycobacteria were obtained in case of suspected tuberculosis. CNB were performed on all cases except those with an on-site diagnosis of either epithelial carcinoma of known origin or tuberculosis. * Flow cytometry was performed on all cases with an on-site diagnosis of possible non-Hodgkin's lymphoma. USTTFNA = ultrasound-assisted transthoracic fine needle aspiration; $\mathrm{ROSE}=$ rapid on-site evaluation; US-CNB = ultrasound-assisted cutting needle biopsy; $\mathrm{TB}=$ tuberculosis; $\mathrm{AFB}=$ acid-fast bacilli (stain); NSCLC $=$ non-small cell lung cancer; SCLC $=$ small cell lung cancer.

the support of a specialist radiologist. The preferred patient position for the procedure was supine, using a standard $3.75-\mathrm{MHz}$ sector probe in a parasternal approach. The interface between the intrathoracic mass lesion and chest wall was identified. An interface of at least $1 \mathrm{~cm}$ in two dimensions visible throughout inspiration and expiration in an area not covered by bony elements was considered the minimal requirement for a US-assisted procedure. Procedures were performed 'freehand' (not under direct US guidance). The intended site was marked, and the direction, the depth 

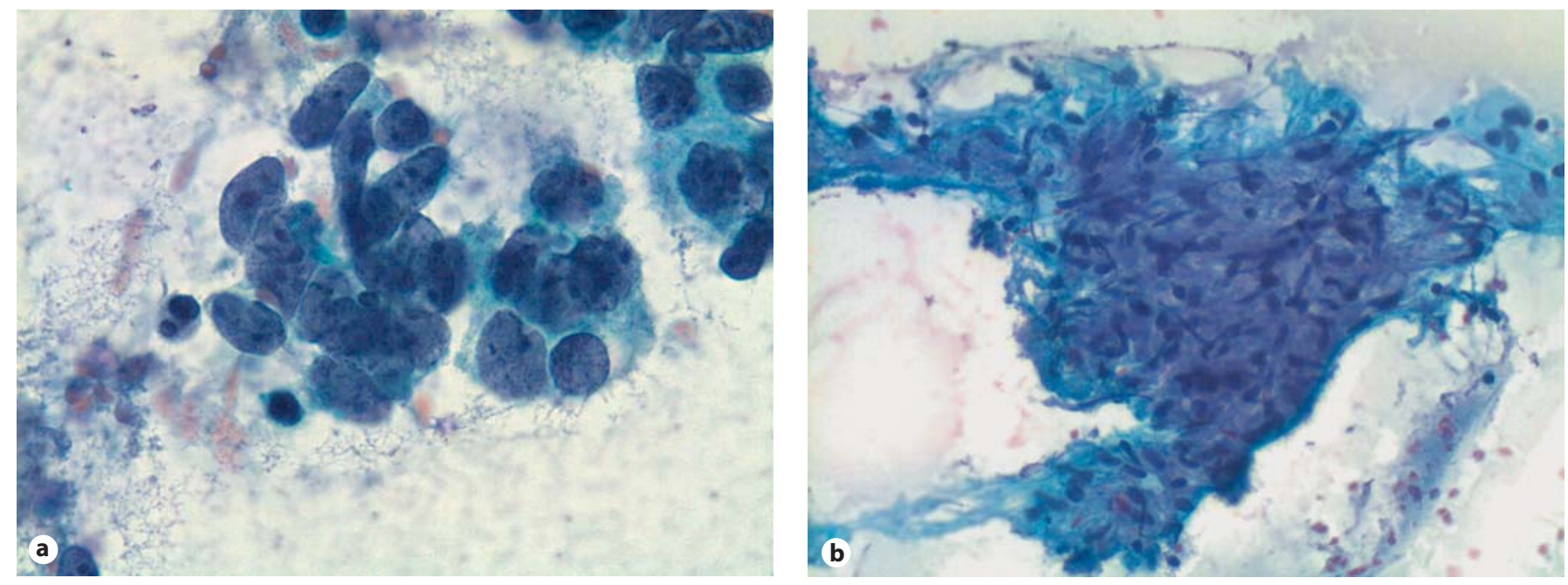

Fig. 3. a An example of an aspirate obtained from a patient with small cell lung cancer showing hyperchromatic nuclei with scanty cytoplasm and nuclear moulding. (Papanicolaou stain, $\times 1,000)$ ). b This aspirate was obtained from a patient with tuberculosis. Note the poorly formed granuloma consisting of epithelioid histiocytes. This slide subsequently stained positive for acid-fast bacilli in the laboratory; cultures confirmed these bacilli to be Mycobacterium tuberculosis. (Papanicolaou stain, $\times 400$ ).

of interest and the safety range for the procedure documented. Care was taken to avoid the major intrathoracic blood vessels and the internal thoracic arteries, as well as any major collateral veins that may have formed in cases with superior vena cava obstruction.

\section{Transthoracic Fine-Needle Aspirations}

Aspirations were performed with 22-G spinal needles of 40 or $90 \mathrm{~mm}$ length as needed (Tae-Cang, Kong Ju City, Korea) connected to a $10-\mathrm{ml}$ syringe under sterile conditions with local anaesthesia (lignocaine 1\%). Aspirates from at least 4 slightly different directions and depths were directly expressed onto slides, smeared and submitted for ROSE using both Diff-Quik (Rapidiff; Clinical Sciences Diagnostics, Southdale, South Africa) and rapid Papanicolaou staining methods [24].

\section{ROSE of Cytology Specimens}

The cytopathologist present in theatre was asked to comment on the presence of diagnostically useful material obtained (fig. 2) and to provisionally type the diagnostically useful specimens into 1 of 4 main categories: (1) epithelial carcinomas of known origin (including non-small cell lung carcinoma, thyroid carcinoma and small cell carcinoma; fig. 3a), (2) other malignancies, (3) probable tuberculous disease (necrotising and/or granulomatous inflammation; fig. 3b) and (4) other benign pathology. We considered specimens with a provisional on-site diagnosis of either epithelial carcinomas of known origin or probable tuberculosis as sufficient for a potential final cytological diagnosis (that is, no histology was obtained). In case of malignancies other than epithelial carcinoma, the cytopathologist was asked to provide a provisional diagnosis where possible and to suggest further investigations, for example flow cytometry for non-Hodgkin's lymphoma or aspirates for mycobacterial cultures in case of suspected tuberculosis.

\section{Cutting Needle Biopsies}

CNB were obtained in the same session immediately following TTFNA in all cases where the provisional on-site diagnosis was not an epithelial carcinoma of a known origin or tuberculosis, provided at least a $1-\mathrm{cm}$ safety range could be assured (that is, no mediastinal organs or blood vessels within $1 \mathrm{~cm}$ of the intended CNB path). Manually operated 14-gauge Tru-cut biopsy needles (Allegiance, Chateaubriand, France) were used. Two or more passes were performed until macroscopically satisfactory material was harvested. These specimens were harvested in $4 \%$ formalin and routinely processed for histological evaluation.

\section{Immediate Post-Procedure Care}

The TTFNA and CNB site were re-examined by means of US immediately after the procedures, and a chest radiograph was obtained if the pre- and post-procedure US findings differed and at the discretion of the attending physician. All patients were observed for at least $2 \mathrm{~h}$ prior to discharge. Minor or major haemorrhage, as well as iatrogenic pneumothoraces, was documented. Major haemorrhage was defined as any haemorrhage that required additional measures above and beyond localised pressure and superficial sutures.

\section{Further Assessment}

All cytology slides were reviewed in the laboratory by a second cytopathologist, who had an array of special stains (including immunocytochemistry and stains for acid-fast bacilli) at his or her disposal, and had to concur with the original cytopathologist prior to issuing a final cytological diagnosis. In case of disagreement a third cytopathologist was consulted to resolve the case. The histological specimens were reviewed by two independent pathologists. Only histological diagnoses, unequivocal cytology in case of epithelial carcinoma or aspirates that were culture positive for 
Table 1. Final diagnoses of all study subjects $(n=45)$

\begin{tabular}{lrr}
\hline Diagnoses & $\mathrm{n}$ & $\%$ \\
\hline Non-small cell lung cancer & & \\
$\quad$ Adenocarcinoma & 6 & 13.3 \\
$\quad$ Squamous carcinoma & 5 & 11.1 \\
$\quad$ Undifferentiated & 1 & 2.2 \\
Small cell lung cancer & 13 & 28.9 \\
Lymphoma & & \\
$\quad$ Hodgkin's lymphoma & 2 & 4.4 \\
$\quad$ B-cell non-Hodgkin's lymphoma & 3 & 6.7 \\
$\quad$ T-cell non-Hodgkin's lymphoma & 2 & 4.4 \\
Other malignancies & & \\
$\quad$ Papillary thyroid carcinoma & 2 & 4.4 \\
$\quad$ Breast cancer & 1 & 2.2 \\
$\quad$ Germ cell tumour (embryonal carcinoma) & 1 & 2.2 \\
$\quad$ Leiomyosarcoma & 1 & 2.2 \\
$\quad$ Pleomorphic sarcoma & 1 & 2.2 \\
$\quad$ Osteosarcoma & \\
Thymoma & 1 & 2.2 \\
Tuberculosis (adenitis) & 2 & 4.4 \\
Retrosternal thyroid (normal thyroid tissue) & 2 & 4.4 \\
Complicated hydatid cyst & 1 & 2.2 \\
\end{tabular}

1 The single cases of breast cancer and osteosarcoma were deemed to be metastatic, as both were diagnosed in patients who had been treated for primary neoplasms in the preceding 2 years.

Mycobacterium tuberculosis were accepted as the gold standard for statistical analyses. Patients in whom the initial investigations (TTFNA and CNB) failed to yield a diagnosis were referred for surgical biopsy. All patients were followed up until a tissue diagnosis could be confirmed, and in the case of bronchogenic carcinoma, until they were staged according to the 2009 International Association for the Study of Lung Cancer staging system [25].

\section{Statistical Analysis}

Descriptive statistics as well as Fisher's exact test were employed. A p value of $\leq 0.05$ in a two-tailed test was considered significant. Unless stated otherwise, data are displayed as means \pm standard deviation.

\section{Results}

\section{Patients}

Over the 1-year period (July 2009 to June 2010) we enrolled 45 consecutive patients (49.5 \pm 27.7 years, 24 males). No patient was excluded or declined to give consent. In total, 20 patients (44\%) had clinical evidence of SVC syndrome. Bronchogenic carcinoma $(n=25)$ was responsible for the majority of anterosuperior mass lesions (table 1), with small cell lung cancer being the most fre- quent final established diagnosis $(n=13)$. Eight of the patients with small cell lung cancer were considered to have limited disease. Of the patients with non-small cell lung cancer, all had either stage IIIB $(n=7)$ or stage IV disease $(n=5)$.

\section{Imaging}

Distinct lesions confined to the anterosuperior mediastinum were present in 26 patients and a further 19 had more extensive mediastinal involvement on CT scan (predominantly involving the anterosuperior compartment). The maximum anteroposterior dimensions ranged from 24 to $119 \mathrm{~mm}$, with a mean of $69 \mathrm{~mm}( \pm 19$ $\mathrm{mm})$. All lesions were visible at US and TTFNA was possible in all patients enrolled.

\section{Fine-Needle Aspirations}

Specimens that were considered potentially useful by the on-site pathologist were obtained from 37 of the 45 subjects (82.2\%). Of these, the TTFNA were considered as being sufficient for a cytological diagnosis (provisional diagnosis either epithelial carcinoma or probable tuberculosis adenitis) in 27 patients (60.0\%). In total, 26 onsite diagnoses $(57.8 \%)$ corresponded with the final diagnoses (table 2), including single cases of breast carcinoma, papillary thyroid carcinoma and normal thyroid tissue. Two cases of small cell lung cancer were provisionally erroneously typed as non-small cell lung cancer. Provisional on-site diagnoses made in the remaining patients with cellular aspirates (not considered sufficient) included possible lymphoma $(\mathrm{n}=3)$, possible thymoma $(\mathrm{n}=1)$ and malignant cells of unknown origin $(n=5)$.

A final laboratory cytological diagnosis was possible in 33 patients (73.3\%) after incorporating immunocytochemistry, flow cytometry and stains for acid-fast bacilli (table 2). US-assisted TTFNA was diagnostic in 26 of 28 patients with epithelial carcinoma (92.8\%), with 23 of 25 lung cancers, 2 papillary thyroid carcinomas and 1 case of metastatic breast cancer having diagnostic morphological and immunocytochemical features. Included in the 2 cases of papillary thyroid carcinoma was 1 case that was typed on-site as 'malignant cells of unknown origin' (laboratory cytology and histology were diagnostic). Both patients with tuberculosis had acid-fast bacilli on the smears and were culture positive for M. tuberculosis. USassisted TTFNA was therefore diagnostic in 28 of 30 cases of either epithelial carcinoma or tuberculosis. Three cases yielding malignant cells of unknown origin could not be accurately subtyped on cytology (the final histological diagnoses were germ cell tumour, leiomyosarco- 
Table 2. Diagnostic yield in order of procedural sequence

\begin{tabular}{|c|c|c|c|c|}
\hline Diagnoses & TTFNA: ROSE & TTFNA: laboratory & $\mathrm{CNB}$ & Surgical biopsy \\
\hline \multicolumn{5}{|l|}{ Epithelial carcinoma } \\
\hline Small cell lung cancer $(\mathrm{n}=13)$ & $11 / 13(84.6 \%)^{1}$ & $13 / 13(100 \%)$ & - & - \\
\hline Non-small cell lung cancer $(n=12)$ & $10 / 12(83.3 \%)$ & $10 / 12(83.3 \%)$ & $2 / 2(100 \%)$ & - \\
\hline Other $(\mathrm{n}=3)$ & $2 / 3(66.7 \%)$ & $3 / 3(100 \%)$ & $1 / 1(100 \%)$ & - \\
\hline Lymphoma $(\mathrm{n}=7)$ & $0 / 7(0 \%)$ & $3 / 7(42.9 \%)$ & $5 / 6(83.3 \%)^{2}$ & $2 / 2(100 \%)$ \\
\hline \multicolumn{5}{|l|}{ Non-neoplastic pathology } \\
\hline Tuberculosis $(n=2)$ & $2 / 2(100 \%)$ & $2 / 2(100 \%)$ & - & - \\
\hline Other $(\mathrm{n}=2)$ & $1 / 2(50 \%)$ & $1 / 2(50 \%)$ & $1 / 2(50 \%)$ & $1 / 1(100 \%)$ \\
\hline All patients $(n=45)$ & $26 / 45(57.8 \%)$ & $33 / 45(73.3 \%)^{3}$ & $15 / 17(88.2 \%)$ & $3 / 3(100 \%)$ \\
\hline
\end{tabular}

${ }^{1}$ Two cases of small cell lung cancer were provisionally erroneously typed as non-small cell lung cancer and therefore did not undergo CNB.

${ }^{2}$ No CNB was performed in one case due to safety concerns.

${ }^{3}$ A cytological diagnosis on TTFNA specimens were more likely to be made in epithelial carcinomas and tuberculosis (28/30) than all other diagnoses $(5 / 15, \mathrm{p}<0.001)$.

ma and osteosarcoma). Only 5 of the remaining 15 patients (33.3\%) had accurate cytological diagnoses, and the diagnoses made were diffuse large B-cell lymphoma $(\mathrm{n}=2)$, T-cell lymphoblastic lymphoma $(\mathrm{n}=1)$, thymoma $(\mathrm{n}=1)$ and normal thyroid tissue $(\mathrm{n}=1)$. US-assisted TTFNA was therefore more likely to be diagnostic in patients with either epithelial carcinoma or tuberculosis than in patients with all other diagnoses $(\mathrm{p}<0.001)$.

\section{Cutting Needle Biopsies}

US-assisted CNB were performed in all but one patient with insufficient on-site cytology (in a single case a $1-\mathrm{cm}$ safety range could not be assured). Diagnostic histology was obtained from 15 of 17 patients who underwent CNB (88.2\%). Laboratory cytology was also non-diagnostic in both patients with negative histology and in the single case where $\mathrm{CNB}$ was deferred. The combined approach of US-assisted TTFNA with ROSE and CNB (where indicated) therefore yielded a diagnosis in 42 patients (93.3\%).

\section{Complications}

All procedures were well tolerated and no pneumothoraces were noted. Only one case of minor haemorrhage necessitating a single superficial suture following a CNB was observed.

\section{Further Investigations}

Three patients were referred for surgical biopsy. The diagnoses made in these three cases were Hodgkin's lym- phoma (nodular sclerosing), non-Hodgkin's lymphoma (diffuse large B-cell lymphoma) and complicated hydatid cyst (Echinococcus granulosus). No further invasive diagnostic procedures were deemed necessary in the $24 \mathrm{pa}$ tients with lung cancer.

\section{Discussion}

Using a sequential diagnostic approach of US-assisted TTFNA which was immediately followed by US-assisted CNB where indicated, we were able to diagnose $93.3 \%$ of all patients with anterosuperior mediastinal masses after a single visit to theatre and without the aid of a specialist radiologist or thoracic surgeon. TTFNA yielded a final cytological diagnosis in $73.3 \%$, and was more likely to be diagnostic in the cases of epithelial carcinoma and tuberculosis than all other diagnoses $(\mathrm{p}<0.001)$. CNB yielded diagnostic histology in $88.2 \%$. Furthermore, all procedures were well tolerated and we observed no pneumothoraces or major haemorrhage.

Saito and co-workers were able to diagnose 31 of 45 mediastinal masses by means of US-guided needle biopsies in their landmark study [14]. Yang et al. subsequently found Tru-cut needles to have a diagnostic yield of $88.9 \%$ for mediastinal tumours [15]. The same investigators also pioneered the supraclavicular approach for USguided biopsies of superior mediastinal tumours [16]. Sawhney et al. reported an even higher sensitivity, as they 
were able to diagnose all 25 patients with mediastinal masses by means of a Tru-cut needle [17]. Samad and coworkers reported a more modest yield of $80.5 \%$ [18]. Comparable findings were subsequently reported by other investigators [19-21]. Despite the fact that our sample size is on par with these studies, the relatively small numbers limit meaningful statistical comparisons between the various aetiologies. Studies that included more than 40 patients reported a $1-6 \%$ complication rate from CNB, with pneumothoraces, haemothoraces and haemoptysis the most common serious complications [14, 15, 18-20].

Although our overall sensitivity is on par with the above-mentioned reports, our study design was unique in that we utilised ROSE to limit CNB to cases where cytology was less likely to provide a definitive diagnosis and thereby potentially limiting complications and cost. This approach has been validated for epithelial carcinomas and tuberculosis, where ROSE has been shown to have a high sensitivity for identifying diagnostic material and suggesting a provisional diagnosis [10-12, 26, 27]. Although cytology may be diagnostic in other types of pathology, further investigations are often required and the value of ROSE is therefore less well defined [28]. We decided upfront to acquire tissue samples for histology in all other diagnoses. As expected, we found that TTFNA with ROSE was superior for epithelial carcinoma and tuberculosis compared to all other diagnoses, which arguably justifies such an approach. We did not perform ROSE of CNB specimens with a touch prep as it would not have aided in the identification of candidates for CNB, would have lengthened the procedure time and potentially jeopardised the core specimens, which are often fragile (unlike sentinel lymph nodes). Moreover, we anticipated that CNB (irrespective of ROSE) would have a high yield based on previous work [10-12, 14-21].

We encountered a number of unexpected findings with regard to the final diagnoses made. We anticipated that tuberculous lymphadenitis may be responsible for a higher percentage of lesions, given the fact that the local incidence of pulmonary tuberculosis is 940 cases per 100,000 population and more than $50 \%$ of all new cases of tuberculosis are co-infected with the human immunodeficiency virus $[29,30]$. Although thymomas and lymphomas are traditionally considered the most frequent causes of anterosuperior mediastinal mass lesions [1,31], we found that more than half of our patients had lung cancer, the commonest diagnosis being small cell lung cancer. Approximately 5\% of all lung cancers present with mediastinal mass lesions [32, 33]. In fact, 23 of 302 lung cancer patients treated at our institution in the year preceding our study presented with mediastinal mass lesions (unpublished data). We actively recruited patients with anterosuperior mediastinal mass lesions, irrespective of their respective clinical presentation, and our inclusion criteria did not differ from most published series [14-18, 20]. Historically, however, clinicians have opted for bronchoscopy with transbronchial needle aspirations in the setting of probable lung cancer with central lesions [34], which conceivably introduced a selection bias in most reported series of surgical or minimally invasive biopsies [1-6, 31]. There is unfortunately a paucity of local data on the prevalence of the various aetiologies of anterosuperior mediastinal masses. Although not specifically designed to address this, our data suggest small cell lung cancer to be the commonest cause of anterosuperior mediastinal mass lesions in our population.

A single-session minimally invasive approach has certain limitations and risks not addressed in our study. Albeit exceedingly rare, some case reports implicated needle biopsies of early stage thymoma in seeding into the chest wall $[35,36]$. It may therefore be advisable to offer primary surgical resection to patients with a high suspicion of thymoma in order not to breach the capsule.

In conclusion, we found a single-session sequential approach of US-assisted TTFNA with ROSE followed by $\mathrm{CNB}$, where indicated, to have a high diagnostic yield for anterosuperior mediastinal masses. On-site evaluation provided important guidance for the need for $\mathrm{CNB}$, as the yield of US-assisted TTFNA alone was found to be significantly higher in patients with epithelial carcinomas and tuberculosis than all other diagnoses, justifying the routine performance of CNB in the latter group. This approach is safe and offers a less invasive alternative to surgical biopsy.

\section{Acknowledgement}

The authors would like to thank Prof. Martin Kidd (The Centre for Statistical Consultation, University of Stellenbosch) for his assistance with the statistical analysis of study data.

\section{Financial Disclosure and Conflicts of Interest}

The ultrasound equipment was acquired with funds donated by the Holland Stellenbosch Medical Foundation. 


\section{References}

1 Strollo DC, Rosado de Christenson ML, Jett JR: Primary mediastinal tumors. Part 1: tumors of the anterior mediastinum. Chest 1997;112:511-522.

$>2$ Mineo TC, Ambrogi V, Nofroni I, Pistolese C: Mediastinoscopy in superior vena cava obstruction: analysis of 80 consecutive patients. Ann Thorac Surg 1999;68:223-226.

$\checkmark 3$ Dosios T, Theakos N, Chatziantoniou C: Cervical mediastinoscopy and anterior mediastinoscopy in superior vena cava. Chest 2005;128:1551-1556.

4 Gossot D, Toledo L, Celerier M: The thoracoscope as diagnostic tool for solid mediastinal masses. Surg Endosc 1996;10:504-507.

$>5$ Hajjar W, Elmedany Y, Bamousa A, Saladein M, Ashour M, Fouda M, Al-Kattan K: Diagnostic Yield of Mediastinal Exploration. Med Principles Pract 2002;11:210-213.

$\checkmark 6$ Pompeo E, Tacconi F, Mineo TC: Awake Video-Assisted Thoracoscopic Biopsy in Complex Anterior Mediastinal Masses. Thorac Surg Clin 2010;20:225-233.

$>7$ Koegelenberg CFN, Diacon AH, Bolliger CT: Transthoracic Ultrasound of the Chest Wall, Pleura, and the Peripheral Lung; in: Bolliger, CT, Herth FJF, Mayo PH, Miyazama T, Beamis JF (eds): Progress in Respiratory Research, 2009, vol 37, pp 22-33.

$>8$ Diacon AH, Theron J, Bolliger CT: Transthoracic ultrasound for the pulmonologist. Curr Opin Pulm Med 2005;11:307-312.

9 Koegelenberg CF, Bolliger CT, Theron J, Walzl G, Wright CA, Louw M, Diacon AH: A direct comparison of the diagnostic yield of ultrasound-assisted Abrams and Tru-cut needle biopsies for pleural tuberculosis. Thorax 2010 [Epub ahead of print].

$>10$ Diacon AH, Schuurmans MM, Theron J, Wright CA, Bolliger CT: Safety and yield of ultrasound assisted transthoracic biopsy performed by pulmonologists. Respiration 2004;71:519-522.

$\checkmark 11$ Diacon AH, Theron J, Schubert P, Brundyn K, Louw M, Wright CA, Bolliger CT: Ultrasound-assisted transthoracic biopsy: fineneedle aspiration or cutting-needle biopsy? Eur Respir J 2007;29:357-362.

$\checkmark 12$ Koegelenberg CF, Bolliger CT, Plekker D, Wright CA, Brundyn K, Louw M, Schubert P, van den Heuvel MM, Diacon AH: Diagnostic yield and safety of ultrasound-assisted biopsies in superior vena cava syndrome. Eur Respir J 2009;33:1389-1395.
13 Koegelenberg CFN, Bolliger CT, Irusen EM, Wright CA, Louw M, Schubert PT, Diacon $\mathrm{AH}$ : The diagnostic yield and safety of ultrasound-assisted transthoracic fine-needle aspiration of drowned lung. Respiration 2011; 81:26-31.

14 Saito T, Kobayashi H, Sugama Y, Tamaki S, Kawai T, Kitamura S: Ultrasonically guided needle biopsy in the diagnosis of mediastinal masses. Am Rev Respir Dis 1988;138:679684.

15 Yang PC, Chang DB, Yu CJ, Lee YC, Wu HD, Kuo SH, Luh KT: Ultrasound-guided core biopsy of thoracic tumors. Am Rev Respir Dis 1992;146:763-767.

16 Yang PC, Chang DB, Lee YC, Yu CJ, Kuo SH, Luh KT: Mediastinal malignancy: ultrasound guided biopsy through the supraclavicular approach. Thorax 1992;47:377-380.

17 Sawhney S, Jain R, Berry M: Tru-Cut biopsy of mediastinal masses guided by real-time sonography. Tru-Cut biopsy of mediastinal masses guided by real-time sonography. Clin Radiol 1991;44:16-19.

18 Samad SA, Sharifah NA, Zulfiqar MA, Maimunah A, Yahya A, Zainudin W: Ultrasound guided percutaneous biopsies of suspected mediastinal lesions. Med J Malaysia 1993;48: 421-426.

19 Andersson T, Lindgren PG, Elvin A: Ultrasound guided tumour biopsy in the anterior mediastinum. An alternative to thoracotomy and mediastinoscopy. Acta Radiol 1992; 33:423-426.

20 Ikezoe J, Morimoto S, Arisawa J, Takashima S, Kozuka T, Nakahara K: Percutaneous biopsy of thoracic lesions: value of sonography for needle guidance. Am J Roentgenol 1990; 154:1181-1185.

21 Tikkakoski T, Lohela P, Leppänen M, ApajaSarkkinen M, Typpäo T, Mäkäräinen H: Ultrasound-guided aspiration biopsy of anterior mediastinal masses. J Clin Ultrasound 1991;19:209-214.

22 Schubert P, Wright CA, Louw M, Brundyn K, Theron J, Bolliger CT, Diacon AH: Ultrasound-Assisted Transthoracic Biopsy: Cells or Section? Diagn Cytopathol 2005;33:233237.

23 Fraser RS, Pare JAP, Fraser RG: The normal chest; In: Fraser RS, Pare JAP, Fraser RG (eds): Synopsis of diseases of the chest. 2nd Edn. Philadelphia, WB Saunders, 1994, pp 1-116.

24 Keebler KM: Cytopathology techniques; In Bibbo M (ed): Comprehensive Cytopathology. 2nd Edn. Philadelphia, WB Saunders, 1997, pp 881-906.
25 Detterbeck FC, Boffa DJ, Tanoue LT: The New Lung Cancer Staging System. Chest 2009; 136:260-271.

26 Diacon AH, Koegelenberg CF, Schubert P, Brundyn K, Louw M, Wright CA, Bolliger CT: Rapid on-site evaluation of transbronchial aspirates: randomised comparison of two methods. Eur Respir J 2010;35:12161220 .

-27 Wright CA, Warren RM, Marais BJ: Fine needle aspiration biopsy: an undervalued diagnostic modality in paediatric mycobacterial disease. Int J Tuberc Lung Dis 2009;13: 1467-1475.

28 Swart GJ, Wright CA: The utilization of fine needle aspiration biopsy (FNAB) and flow cytometry (FC) in the diagnosis and classification of non-Hodgkin B-cell and T-cell lymphomas. Transfus Apher Sci 2010;42: 199-207.

29 WHO Press: World Health Organization report. Global tuberculosis control: surveillance, planning, finances. Geneva; 2008:19.

-30 Abdool Karim SS, Churchyard GJ, Abdool Karim Q, Lawn SD: HIV infection and tuberculosis in South Africa: an urgent need to escalate the public health response. Lancet 2009;374:921-933.

-31 Davis RD Jr, Oldham HN Jr, Sabiston DC Jr: Primary cysts and neoplasms of the mediastinum: recent changes in clinical presentation, methods of diagnosis, management, and results. Ann Thorac Surg 1987;44:229237.

32 Quinn D, Gianlupi A, Broste S: The changing radiographic presentation of bronchogenic carcinoma with reference to cell types. Chest 1996;110:1474-1479.

33 Rosado-de-Christenson ML, Templeton PA, Moran CA. Bronchogenic carcinoma: radiologic-pathologic correlation. RadioGraphics 1994; 14:429-446.

34 Rivera MP, Mehta AC: Initial Diagnosis of Lung Cancer. ACCP Evidence-Based Clinical Practice Guidelines ( $2^{\text {nd }}$ Edition). Chest 2007;132(suppl):131S-148S.

-35 Fujiwara K, Matsumura A, Tanaka H, Ohmori K, Yamamoto S, Iuchi K: Needle tract implantation of thymoma after transthoracic needle biopsy. Kyobu Geka 2003;56:448451.

36 Nagasaka T, Nakashima N, Nunome H: Needle tract implantation of thymoma after transthoracic needle biopsy. J Clin Pathol 1993;46:278-279. 